\title{
Subacute sclerosing panencephalitis - current perspectives
}

This article was published in the following Dove Press journal: Pediatric Health, Medicine and Therapeutics

\author{
Sidra K Jafri \\ Raman Kumar \\ Shahnaz H Ibrahim \\ Department of Pediatrics and Child \\ Health, Aga Khan University Hospital, \\ Karachi, Pakistan
}

\begin{abstract}
Subacute sclerosing panencephalitis is a progressive neurodegenerative disease. It usually occurs $7-10$ years after measles infection. The clinical course is characterized by progressive cognitive decline and behavior changes followed by focal or generalized seizures as well as myoclonus, ataxia, visual disturbance, and later vegetative state, eventually leading to death. It is diagnosed on the basis of Dyken's criteria. There is no known cure for subacute sclerosing panencephalitis to date, but it is preventable by ensuring that an effective vaccine program for measles is made compulsory for all children younger than 5 years in endemic countries.
\end{abstract}

Keywords: SSPE, progressive, vaccine, preventable

\section{Introduction}

Subacute sclerosing panencephalitis, commonly known as SSPE, is a progressive neurodegenerative disease caused by the persistence of measles infection commonly seen in children and young adults. ${ }^{1}$ SSPE was previously known as Dawson's inclusion body encephalitis as Dawson in 1933 and 1934 reported cellular inclusions in the cerebral lesions of patients with SSPE, thus resulting in this disease being labeled as Dawson inclusion body encephalitis. ${ }^{2}$ Ten years later, Brain et $\mathrm{al}^{3}$ reported similar conditions with further case reports, and later, the term SSPE was coined. Electron microscopic evidence of paramyxovirus was established between 1967 and 1969.

Measles is a highly contagious RNA virus of the paramyxoviridae family and the genus morbillivirus. It is an airborne disease and transmitted via nasopharyngeal droplets. The virus is highly lymphotropic, affecting dendritic cells, alveolar macrophages, and subsets of $\mathrm{B}$ and $\mathrm{T}$ cells in the lymphoid tissue of the lower respiratory tract, and later, it infiltrates the epithelium of the upper respiratory tract. Acute complications include otitis media, pneumonia, diarrhea, and postinfectious encephalitis. ${ }^{5}$ Neurological complications of measles involve post-measles encephalitis, measles inclusion body encephalitis, transverse myelitis, and SSPE. ${ }^{6}$ The risk of serious complications and death is increased in children younger than 5 years and adults older than 20 years. ${ }^{7}$ This disease is preventable, and immunization against measles via live attenuated vaccine has been available for more than 45 years. ${ }^{8}$

SSPE usually occurs 7-10 years after measles infection, but the latency varies from 1 month to 27 years. ${ }^{9}$ A shorter latency has been reported in intrafamilial cases of SSPE as well as in children who were affected at an earlier ( $<2$ years) age such that the incidence was 18/100,000 in children younger than 5 years and 1.1/100,000 in those children with measles after 5 years. ${ }^{10,11}$ It is caused by the cerebral involvement of the
Correspondence: Shahnaz H Ibrahim Department of Pediatrics and Child Health, Aga Khan University, Stadium Road, PO Box 3500, Karachi, Pakistan

Tel +922134864732

Fax+92 21 34932095

Email shahnaz.ibrahim@aku.edu 
measles virus, which causes destruction of the neurons. The pathogenesis of SSPE is yet to be elucidated, but it has been shown to be caused by the wild strains and not by the vaccine strains, which has been supported by genetic studies. ${ }^{12}$ The strains of measles virus causing SSPE have multiple point mutations in their genomes, especially in the gene encoding for the matrix protein gene. ${ }^{13}$ Studies have shown that the capacity of wild-type measles virus strains to cause SSPE results from their increased capacity to spread and that this is partially due to a tri-residue motif, P64, E89, and A209 (PEA), in their M proteins, which is absent in vaccine and lab-adapted strains. ${ }^{14}$ Mutations in M proteins result in interference with the assembly of new viral particles and their budding, which form viral particles that are transmitted via ribonucleic protein with a trans-synaptic spread..$^{15}$ Immaturity of the cellular immunity mechanism has been critical as suggested by earlier age of acquiring measles infection resulting in higher incidences of SSPE. ${ }^{11}$ Although other viruses have been studied in association with SSPE, there is no data to support their role in causation of the disease. ${ }^{13}$

The worldwide prevalence of SSPE has declined to 1 per 100,000 cases of measles due to better immunization coverage in developed countries. ${ }^{7}$ There is not only geographical variation in the prevalence of SSPE but economic development also contributes to the falling trends. Developed countries such as USA have reported an incidence of 6.5-11 cases per 100,000 acute measles infections. ${ }^{12}$ European countries like Turkey have reported an incidence of 2.2 cases per million in their population. ${ }^{16}$ Developing countries like Pakistan have reported an estimated incidence of 10 cases per million in their population. ${ }^{17}$ The highest rate that has ever been reported is from Papua New Guinea, which is 51 cases per one million during 2007-2009. ${ }^{18}$ Although there is no gender predisposition, but SSPE has been seen more commonly in boys. ${ }^{19}$ The risk of SSPE is higher if the onset of measles is at a younger age, in low socioeconomic class, in cases with low parental education and large family size. ${ }^{4}$

The clinical course is characterized by progressive cognitive decline and behavior changes followed by focal or generalized seizures as well as myoclonus, ataxia, visual disturbance, and later vegetative state. ${ }^{20,21}$ Patients suffering from SSPE die within few years of initial clinical presentation although there have been rare case reports of spontaneous remission. ${ }^{20}$ Epilepsy has been reported in one-third of the patients with SSPE. ${ }^{22}$

Jabbour et $\mathrm{al}^{23}$ have divided the clinical manifestations into four stages. Stage I is characterized by irritability, dementia, social withdrawal, lethargy, and regression of speech; stage II is characterized by various types of movement disorders such as dyskinesia, dystonia, and myoclonus. Stage III is consistent with extrapyramidal symptoms, decerebrate posturing, and spasticity, while the stage IV is characterized by loss of function of cerebral cortex with signs of vegetative state, autonomic failure, and akinetic mutism. Atypical presentations have been described including isolated psychiatric manifestations, poorly controlled seizures, and isolated extrapyramidal symptoms, such as dystonia, chorea, hemi-parkinsonism, etc. Occasionally, a stroke-like onset has also been described. There may be a transient plateau period or slight improvement in some patients, but classically it has a relentless pattern associated with high mortality. ${ }^{24}$ Differential diagnoses include epilepsy and psychiatric illnesses in early stages along with other viral encephalitides, atypical multiple sclerosis, leukodystrophies, variant CreutzfeldtJakob disease, and neurometabolic encephalopathies..$^{25}$ The diagnosis of SSPE is often considered late in developed countries owing to its rare occurrence and the nonspecific clinical manifestations at onset. ${ }^{26}$

Visual loss as an initial presentation has also been described. ${ }^{27}$ Ocular findings are seen in almost $50 \%$ of cases. A variety of neuro-opthalmological and retinal findings are associated with SSPE, and the classic lesion is focal necrotizing macular retinitis. There may be retinal hemorrhages, edema, and detachment. Vitreal inflammation is not seen in SSPE. Optic disc changes include papillitis, papilledema, and disc pallor. Retinal involvement may settle with time or eventually lead to scarring. Ophthalmic symptoms may precede the neurological symptoms of SSPE. Other symptoms that may occur include cortical blindness, gaze palsies, ptosis, and nystagmus. ${ }^{28}$

The diagnosis is based on the Dyken's criteria, which include two major and four minor criteria. Major criteria include 1) raised anti-measles antibody titers in cerebrospinal fluid (CSF) greater than or equal to $1: 4$ or ratio greater than or equal to 1:256 in serum, and 2) typical or atypical clinical history (typical includes acute or rapidly progressive, subacute progressive, chronic progressive, and chronic relapsing-remitting, while atypical includes seizures, prolonged stage I, and unusual age of presentation that is either in infancy or adulthood). Minor criteria include the following: 1) characteristic electroencepahlograhic findings that include periodic, generalized, bilaterally synchronous and symmetrical high-amplitude slow waves that recur at regular intervals of 5-15 seconds called periodic slow-wave complexes also known as "Radermecker" complexes (Figure 1). The interval between complexes is generally fixed, but variation in the 
interval between periodic discharges may also be seen, also known as pseudo-periodic or quasi-periodic discharges..$^{29,30} 2$ ) CSF globulin levels greater than $20 \%$ of the total CSF protein.

3) Characteristic histopathological findings on brain biopsy including inflammatory changes in the meninges and cerebral parenchyma necrotizing leukoencephalitis with diffuse demyelination; viral inclusion bodies in neurons; oligodendrocytes and astrocytes; neuronal loss; and astrocytosis. 4) Specialized molecular diagnostic test to identify wild-type measles virus mutated genome. Usually two major criteria plus one minor criterion are required, but if the features are atypical, then histopathological or molecular evidence may be required. ${ }^{29,30}$ Interestingly, histopathological studies carried out after autopsy of individuals without SSPE showed approximately $20 \%$ having detectable measles virus in the brain. ${ }^{31}$ However, just the presence of RNA without satisfaction of Dyken's criteria would not mean that the person has SSPE.

Neuroimaging may be helpful but is not characteristic of SSPE. During the early stages, magnetic resonance (MR)

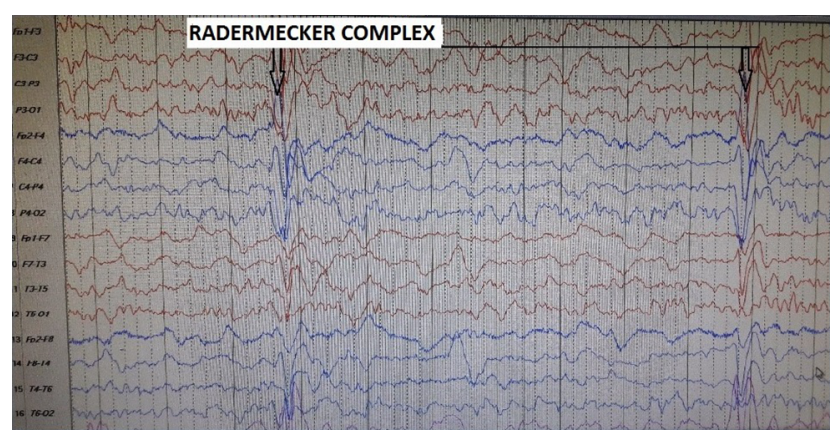

Figure I EEG of a patient with SSPE

Note: Longitudinal bipolar montage showing periodic slow waves also known as the "Radermecker" complexes.

Abbreviations: EEG, electroencephalogram; SSPE, subacute sclerosing panencephalitis. imaging of the brain may show decreased gray matter volume, especially within the frontotemporal cortex, amygdala, and cingulate gyrus. As the disease progresses, hyperintensities on T2-weighted images in the cerebral cortex, periventricular white matter, basal ganglia, and brainstem may develop (Figure 2A-C). Eventually, the MR images will reveal diffuse cortical atrophy, as evidenced by enlarged sulci and ventriculomegaly. MR spectroscopy findings range from increased choline-to-creatinine ratio and inositol-to-creatinine ratios along with normal $N$-acetyl aspartate-to-creatinine ratios to decreased $N$-acetyl aspartate-to-choline and $N$-acetyl aspartate-to-creatinine ratio correlating to loss of brain volume (Figure 3A and B). ${ }^{19,32-36}$

Currently, there is no cure for SSPE, and eradication by effective vaccination program is considered to be more beneficial and cost-effective than any other high-level forms of control. ${ }^{6}$ Measles-containing vaccines are a part of the childhood vaccination schedule in all countries. Current World Health Organization (WHO) policy is that "Reaching all children with 2 doses of measles vaccine should be standard for all national immunization programs". ${ }^{37}$ Despite this, global coverage with the first dose of measles vaccine has largely stagnated since 2004. Six WHO regions have measles elimination goals for the year 2020, but the World Health Assembly has still not endorsed the eradication of this disease. In 2012, Measles and Rubella Initiative published a Global Measles and Rubella Strategic Plan 2012-2020, which aimed to achieve elimination of these two diseases in 5 WHO regions by 2020. By the end of 2015, none of these milestones had been met. Although the number of countries with measles vaccine 1 coverage of $>90 \%$ has risen between 2010 and 2015, we are still a long way from a global measles eradication. $^{37}$
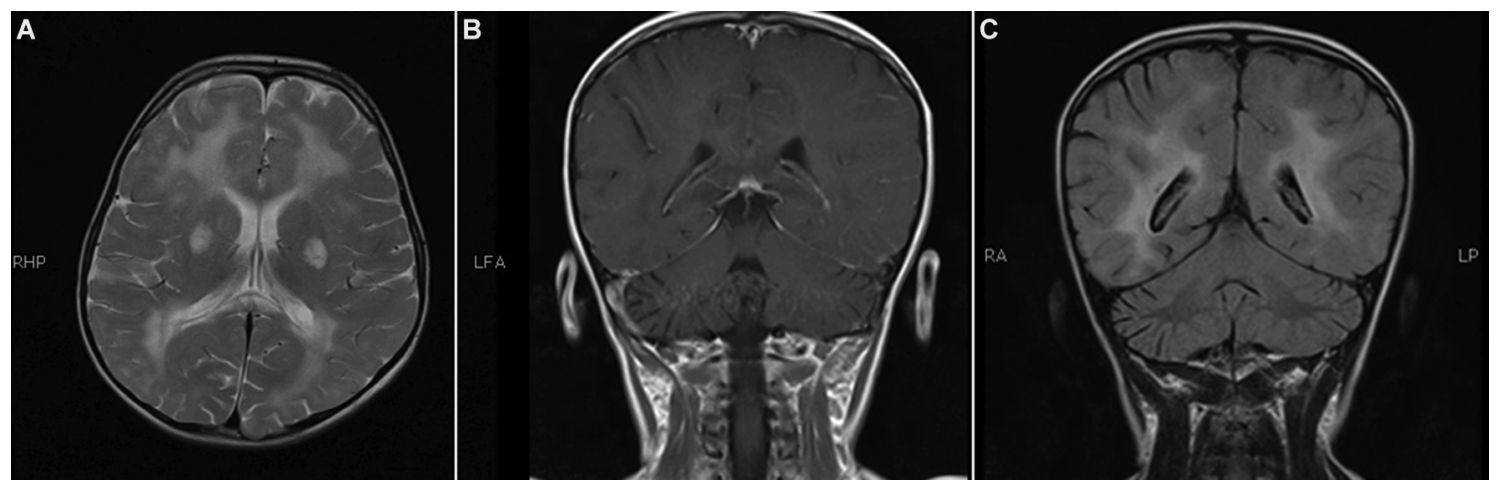

Figure 2 (A-C) The MRI of a 6-year-old girl with SSPE.

Notes: Abnormal signal intensity areas are identified in the periventricular and deep white matter region bilaterally. Abnormal signal are also noted in putamen bilaterally. These areas appear hyperintense on T2-weighted images, hypointense to isointense on TI-weighted images, and there is no evidence of diffusion restriction and no postcontrast enhancement.

Abbreviations: MRI, magnetic resonance imaging; SSPE, subacute sclerosing panencephalitis. 


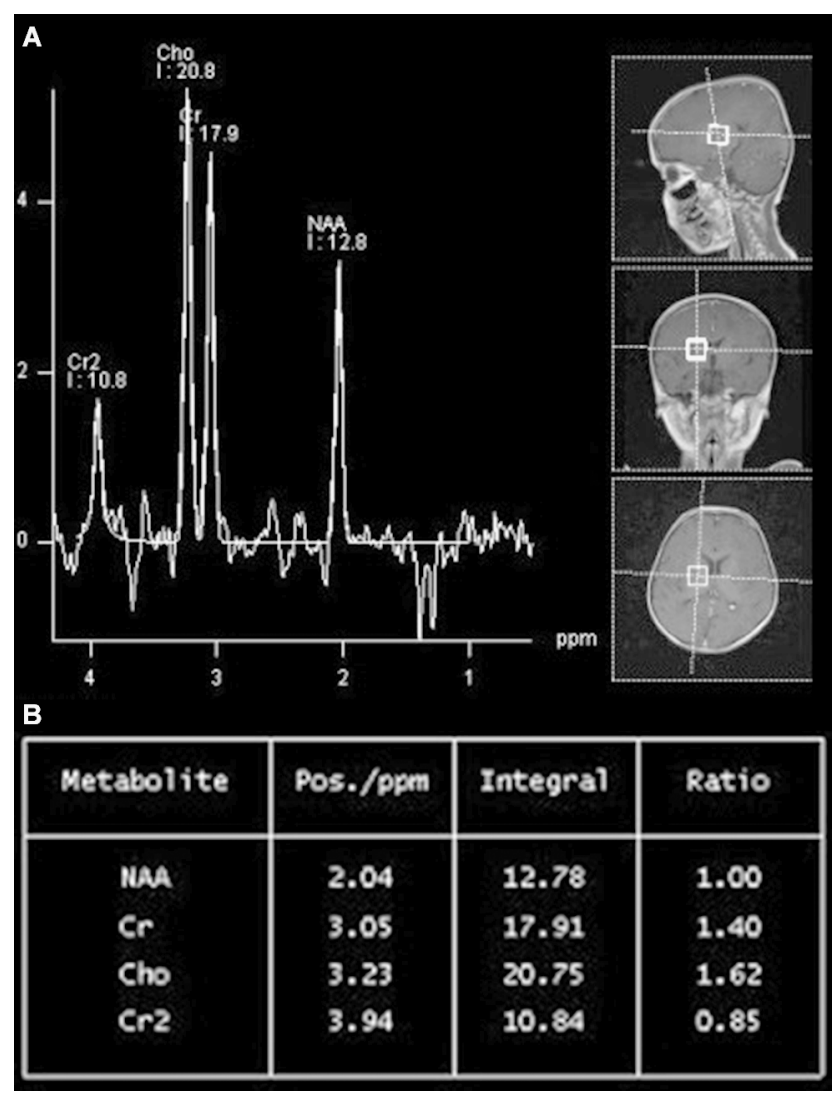

Figure 3 (A and $\mathbf{B}$ ) The MRS of the 6-year-old girl with SSPE.

Notes: MR spectroscopy shows low NAA levels as well as NAA/Cr and NAA/ choline. Patient is the same as seen in Figure 2.

Abbreviations: MR, magnetic resonance; MRS, magnetic resonance spectroscopy; NAA, nacetyl aspartate; $\mathrm{Cr}$, creatinine.

Supportive treatment including management of seizures and other complications is the mainstay. ${ }^{11}$ Divalproate sodium is one of the common antiepileptics employed. ${ }^{38}$ There are no standard treatment protocols for the treatment of SSPE. Antiviral drugs and immunomodulators are used in the treatment of SSPE. Even though there are many drugs that have been tried in the treatment of SSPE, inosine pranobex, interferon alfa, ribavirin, and lamivudine are the most commonly used drugs in routine clinical practice. These have been used either singly or in combinations. Inosine pranobex (Isoprinosine, Inosiplex) is an antiviral drug with immunomodulatory effects. It is a synthetic compound. It is given orally in doses of $100 \mathrm{mg} / \mathrm{kg} /$ day (with a maximum dose of $3,000 \mathrm{mg} /$ day) in three divided doses to patients with SSPE. Abnormalities in serum and urinary uric acid and occasional nausea have been reported with Isoprinosine ${ }^{39}$ Interferon alfa is an immunomodulator drug. It is preferably given via the intraventricular route as it has very poor penetration of the blood-brain barrier. Ribavarin and lamivudine have also been tried with no great success.

Ketogenic diet has also been tried; it was found to temporarily reduce the myoclonic jerks. ${ }^{40}$ Steroids and intravenous immunoglobulin are no longer recommended for the treatment of SSPE.

Future therapies are incorporating antiapoptotic agents, and RNAi is being experimented upon and may be beneficial in future. ${ }^{41}$

The prognosis for SSPE remains guarded. Mortality has been reported in $95 \%$ of the patients. ${ }^{42}$ The average life span of a patient suffering from SSPE is 3.8 years (45 days-12 years) ${ }^{16}$ Another study has proposed that the mean survival in children is about 1 year 9 months to 3 years. ${ }^{11}$

\section{Conclusion}

In short, SSPE is a potentially lethal disease and causes a huge burden both emotionally and financially, affecting not only the family but the country as whole. Furthermore, as this is seen more in the underdeveloped countries, the economic burden to these nations is huge. There is a strong need to improve the vaccination status of countries where the incidence of measles is high as it may be the only way to eradicate this devastating condition. This requires a global and political will and ownership by the individual countries.

\section{Acknowledgment}

The ethical review committee of the Aga Khan University agreed that no patient consent for the use of the figures was needed as patient data was kept anonymous.

\section{Disclosure}

The authors report no conflicts of interest in this work.

\section{References}

1. Ibrahim SH, Amjad N, Saleem AF, Chand P, Rafique A, Humayun KN. The upsurge of SSPE - a reflection of national measles immunization status in Pakistan. J Trop Pediatr. 2014;60(6):50.

2. Dawson JR. Cellular inclusions in cerebral lesions of epidemic encephalitis: second report. Arch Neurol Psych. 1934;31(4):685-700.

3. Brain WR, Greenfield J, Russel DS. Subacute inclusion encephalitis (Dawson type). Brain. 1948;71(4):365-385.

4. Campbell H, Andrews N, Brown K, Miller E. Review of the effect of measles vaccination on the epidemiology of SSPE. Int J Epidemiol. 2007;36(6):1334-1348.

5. Holzmann H, Hengel H, Tenbusch M, Doerr H. Eradication of measles: remaining challenges. Med Microbiol Immunol. 2016;205(3): 201-208.

6. Garg RK. Subacute sclerosing panencephalitis. JNeurol. 2008;255(12): 1861-1871.

7. Strebel PM, Papania MJ, Dayan GH, Halsey NA. Measles vaccine. Vaccines. 2008;5:353-398.

8. Orenstein WA, Strebel PM, Papania M, Sutter RW, Bellini WJ, Cochi SL. Measles eradication: is it in our future? Am J Public Health. 2000;90(10): 1521-1525.

9. Cruzado D, Masserey-Spicher V, Roux L, Delavelle J, Picard F, Haenggeli CA. Early onset and rapidly progressive subacute sclerosing panencephalitis after congenital measles infection. Eur J Pediatr. 2002;161(8): $438-441$. 
10. Sharma V, Gupta VB, Eisenhut M. Familial subacute sclerosing panencephalitis associated with short latency. Pediatr Neurol. 2008;38(3):215-217.

11. Gutierrez J, Issacson RS, Koppel BS. Subacute sclerosing panencephalitis: an update. Dev Med Child Neurol. 2010;52(10):901-907.

12. Bellini WJ, Rota JS, Lowe LE, et al. Subacute sclerosing panencephalitis: more cases of this fatal disease are prevented by measles immunization than was previously recognized. J Infect Dis. 2005;192(10):1686-1693.

13. Anlar B, Pinar A, Anlar FY, et al. Viral studies in the cerebrospinal fluid in subacute sclerosing panencephalitis. J Infect. 2002;44(3):176-180.

14. Kweder H, Ainouze M, Brunel J, Gerlier D, Manet E, Buckland R. Measles virus: identification in the $M$ protein primary sequence of a potential molecular marker for subacute sclerosing panencephalitis. Adv Virol. 2015;2015:769837.

15. Reiss CS. Neurotropic Viral Infections. 2nd ed. Reiss CS, editor. Switzerland: Springer International Publishing; 2016:370.

16. Guler S, Kucukkoc M, Iscan A. Prognosis and demographic characteristics of SSPE patients in Istanbul, Turkey. Brain Dev. 2015;37(6):612-617.

17. Takasu T, Kondo K, Ahmed A, editors. Subacute Sclerosisng Panencephalitis (SSPE) in Karachi, Pakistan: Proceedings of the Third International Symposium on SSPE. Vellore, India: Christian Medical College; 1989.

18. Manning L, Laman M, Edoni H, et al. Subacute sclerosing panencephalitis in Papua New Guinean children: the cost of continuing inadequate measles vaccine coverage. PLoS Negl Trop Dis. 2011;5(1):e932.

19. Buchanan R, Bonthius DJ, editors. Measles virus and associated central nervous system sequelae. Semin Pediatr Neurol. 2012;19(3):107-114.

20. Santoshkumar B, Radhakrishnan K. Substantial spontaneous long-term remission in subacute sclerosing panencephalitis (SSPE). J Neurol Sci. 1998;154(1):83-88.

21. Dyken P. Subacute sclerosing panencephalitis. Current status. Neurol Clin. 1985;3(1):179-196.

22. Jović NJ. Epilepsy in children with subacute sclerosing panencephalitis. Srp Arh Celok Lek. 2013;141(7-8):434-440.

23. Jabbour J, Duenas D, Modlin J. SSPE-clinical staging, course, and frequency. Arch Neurol. 1975;32(7):493-494.

24. Öztürk A, Gürses C, Baykan B, Gökyiğit A, Eraksoy M. Subacute sclerosing panencephalitis: clinical and magnetic resonance imaging evaluation of 36 patients. J Child Neurol. 2002;17(1):25-29.

25. Ichiyama T. Clinical course and findings in and differential diagnosis of subacute sclerosing panencephalitis. Nihon Rinsho. 2007;65(8):1481-1482.

26. Honarmand S, Glaser CA, Chow E, et al. Subacute sclerosing panencephalitis in the differential diagnosis of encephalitis. Neurology. 2004;63(8):1489-1493.

27. Sarkar N, Gulati S, Dar L, Broor S, Kalra V. Diagnostic dilemmas in fulminant subacute sclerosing panencephalitis (SSPE). Indian JPediatr. 2004;71(4):365-367.
28. Tripathy K, Chawla R, Mittal K, Farmania R, Venkatesh P, Gulati S Ophthalmic examination as a means to diagnose subacute sclerosing panencephalitis: an optical coherence tomography and ultrawide field imaging evaluation. Eye Vis. 2017;4(1):1.

29. Andraus MEC, Andraus CF, Alves-Leon SV. Periodic EEG patterns: importance of their recognition and clinical significance. Arq Neuropsiquiatr. 2012;70(2):145-151.

30. Markand ON, Panszi JG. The electroencephalogram in subacute sclerosing panencephalitis. Arch Neurol. 1975;32(11):719-726.

31. Katayama Y, Hotta H, Nishimura A, Tatsuno Y, Homma M. Detection of measles virus nucleoprotein mRNA in autopsied brain tissues. J Gen Virol. 1995;76(12):3201-3204.

32. Praveen-Kumar S, Sinha S, Taly AB, et al. The spectrum of MRI findings in subacute sclerosing panencephalitis with clinical and EEG correlates. J Pediatr Neurol. 2011;9(2):177-185.

33. Akdal G, Baklan B, Çakmakçi H, Kovanlikaya A. MRI follow-up of basal ganglia involvement in subacute sclerosing panencephalitis. Pediatr Neurol. 2001;24(5):393-395.

34. Alkan A, Sarac K, Kutlu R, et al. Early-and late-state subacute sclerosing panencephalitis: chemical shift imaging and single-voxel MR spectroscopy. Am J Neuroradiol. 2003;24(3):501-506.

35. Yüksel D, Diren B, Ulubay H, Altunbaşak Ş, Anlar B. Neuronal loss is an early component of subacute sclerosing panencephalitis. Neurology. 2014;83(10):938-944

36. Jafri SK, Husen Y, Ahmed K, Ibrahim SH. Spectrum of MRI brain findings in subacute sclerosing panencephalitis. Asia Pac J Clin Trials Nerv Syst Dis. 2017;2(4):124.

37. Orenstein WA, Cairns L, Hinman A, Nkowane B, Olivé JM, Reingold AL. Measles and Rubella Global Strategic Plan 2012-2020 midterm review report: background and summary. Vaccine. 2018;36: A35-A42.

38. Rafique A, Amjad N, Chand P, et al. Subacute sclerosing panencephalitis: clinical and demographic characteristics. J Coll Physicians Surg Pak. 2014;24(8):557-560.

39. Kannan L, Garg SK, Arya R, Sankar MJ, Anand V. Treatments for subacute sclerosing panencephalitis. Cochrane Database Syst Rev. 2013:(12): CD010867.

40. Bautista RE. The use of the ketogenic diet in a patient with subacute sclerosing panencephalitis. Seizure. 2003;12(3):175-177.

41. Tatlı B, Ekici B, Özmen M. Current therapies and future perspectives in subacute sclerosing panencephalitis. Expert Rev. 2012;12(4): 485-492.

42. Tomoda A, Nomura K, Shiraishi S, et al. Trial of intraventricular ribavirin therapy for subacute sclerosing panencephalitis in Japan. Brain Dev. 2003;25(7):514-517.
Pediatric Health, Medicine and Therapeutics

\section{Publish your work in this journal}

Pediatric Health, Medicine and Therapeutics is an international, peerreviewed, open access journal publishing original research, reports, editorials, reviews and commentaries. All aspects of health maintenance, preventative measures and disease treatment interventions are addressed within the journal. Practitioners from all disciplines are invited to submit
Dovepress

their work as well as healthcare researchers and patient support groups. The manuscript management system is completely online and includes a very quick and fair peer-review system. Visit http://www.dovepress.com/ testimonials.php to read real quotes from published authors. 